\title{
The communication complexity of private value single item auctions
}

Citation for published version (APA):

Grigorieva, E., Herings, P. J. J., Müller, R. J., \& Vermeulen, A. J. (2004). The communication complexity of private value single item auctions. METEOR, Maastricht University School of Business and Economics. METEOR Research Memorandum No. 050 https://doi.org/10.26481/umamet.2004050

Document status and date:

Published: 01/01/2004

DOI:

10.26481/umamet.2004050

Document Version:

Publisher's PDF, also known as Version of record

\section{Please check the document version of this publication:}

- A submitted manuscript is the version of the article upon submission and before peer-review. There can be important differences between the submitted version and the official published version of record.

People interested in the research are advised to contact the author for the final version of the publication, or visit the DOI to the publisher's website.

- The final author version and the galley proof are versions of the publication after peer review.

- The final published version features the final layout of the paper including the volume, issue and page numbers.

Link to publication

\footnotetext{
General rights rights.

- You may freely distribute the URL identifying the publication in the public portal. please follow below link for the End User Agreement:

www.umlib.nl/taverne-license

Take down policy

If you believe that this document breaches copyright please contact us at:

repository@maastrichtuniversity.nl

providing details and we will investigate your claim.
}

Copyright and moral rights for the publications made accessible in the public portal are retained by the authors and/or other copyright owners and it is a condition of accessing publications that users recognise and abide by the legal requirements associated with these

- Users may download and print one copy of any publication from the public portal for the purpose of private study or research.

- You may not further distribute the material or use it for any profit-making activity or commercial gain

If the publication is distributed under the terms of Article $25 \mathrm{fa}$ of the Dutch Copyright Act, indicated by the "Taverne" license above, 


\title{
The communication complexity of private value single item auctions
}

\author{
Elena Grigorieva* $* \quad$ P.Jean-Jacques Herings ${ }^{\dagger} \quad$ Rudolf Müller ${ }^{\ddagger}$ \\ DRIES VERMEULEN §
}

December 14, 2004

\begin{abstract}
In this paper we present a new auction, the bisection auction, that can be used for the sale of a single indivisible object. We discuss the issue concerning the information revelation requirement of this auction and the associated amount of data that needs to be transmitted. We show that in the truthtelling equilibrium the bisection auction is economical in its demand for information on the valuations of the players. It requires the players to transmit less information bits to the auctioneer than the Vickrey and English auctions. In particular, we prove that for integer valuations uniformly distributed on the interval $[0, L)$ the bisection auction of $n$ players requires in expectation transmission of at most $2 n+\log L$ information bits by the players. Compared with the corresponding number in the Vickrey auction which is $n \log L$, and in the English auction which is on average at least $(1 / 3) n L$, the bisection auction turns out to be the best performer.
\end{abstract}

JEL Codes. C72, D44.

Keywords. Single item auction; communication complexity; information revelation; data transmission.

\section{Introduction}

A classical challenge of auction design has been to develop mechanisms that have an implementation in weakly-dominant strategies resulting in an efficient allocation. Due to the Revelation Principle, focus has mainly been on direct revelation mechanisms (see e.g. [7]). In the private value environment the challenge is considered to be solved since the Vickrey-Clarke-Groves direct mechanism implements the efficient allocation and is incentive-compatible $[1,5,12]$. However, by construction, implementation of a strategy in a direct mechanism requires elicitation of complete and exact preference information. It

*e.grigorieva@ke.unimaas.nl. Department of Quantitative Economics, Universiteit Maastricht, P.O. Box 616, 6200 MD Maastricht, The Netherlands. The author acknowledges support by the Dutch Science Foundation NWO through grant 401-01-101.

${ }^{\dagger}$ p.herings@algec.unimaas.nl. Department of Economics, Universiteit Maastricht, P.O. Box 616, 6200 MD Maastricht, The Netherlands.

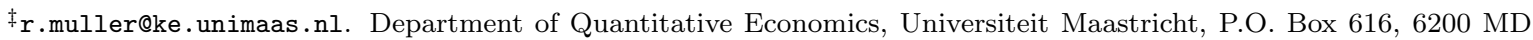
Maastricht, The Netherlands. The author acknowledges support by European Commission through funds for the International Institute of Infonomics.

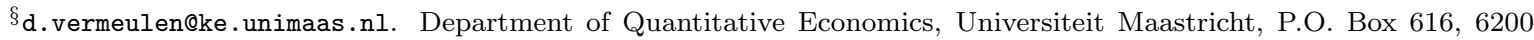
MD Maastricht, The Netherlands. 
has been recognized that the full revelation of bidders' preferences may require a prohibitive amount of communication [8]. Indeed, for example in a combinatorial auction which allocates heterogeneous indivisible items among bidders whose preferences for combinations of items can exhibit complementarities or synergies, every bidder has to report his valuation for each subset of the items, and the number of such subsets is exponential in the number of objects. With 30 items, full revelation of such preferences would require the communication of more than one billion numbers.

Recognition of the communication problem has prompted researchers to examine the trade-off between communication and allocation efficiency. For example, the effect on allocative efficiency of a severe restriction of the amount of communication allowed in a single object auction is studied in Nisan \& Blumrosen [9]. This paper considers the case where each bidder is only allowed to send a single $t$-bit message to the auctioneer, who must then allocate the object and determine the price according to the messages received. The authors determine the optimal auction and show that the loss of efficiency incurred relative to unconstrained auctions is mild. In Rothkopf \& Harstad [11] similar questions are considered in cases of restricting bids to discrete levels in oral auctions. In particular it's shown that for private values independently drawn from the uniform distribution the expected economic inefficiency is approximately proportional to the square of the increment ${ }^{1}$.

In this paper we are concerned with the issue of information (bidders' valuation) revelation and corresponding communication requirements of efficient incentive-compatible auctions for the case of selling a single indivisible object under private values. The best known efficient incentive-compatible auctions are the Vickrey and English auctions. Under the Vickrey auction bidders are allowed to submit one single sealed bid. The bidder with the highest bid is declared to be the winner. He gets the object for a price equal to the second-highest bid that is made. As Vickrey showed in [12], bidding your true valuation for the object is a weakly dominant strategy, independent of the a priori distribution of the valuations of the bidders. In the English auction the auctioneer calls successively higher prices (using an increment equal to one). Initially all bidders are active and, as the auctioneer raises the price, they decide when to drop out. No bidder who has dropped out can become active again. The number of active bidders as well as their bids are not publicly known at any time. The last bidder to remain is the winner and he pays the final ask price. To stay in the auction till the price reaches his valuation is a weakly dominant strategy for each bidder. These two auctions, Vickrey and the above variant of the English auction, are strategically equivalent to each other and the payoffs are identical in both auctions when equivalent strategies are played.

Concerning the information about bidders' valuations to be revealed (under the weakly-dominant truthtelling implementation) we can point out that all valuations in the Vickrey auction and all but the highest valuation in the English auction ${ }^{2}$ are revealed to the auctioneer with a precision up to the very last digit. This is not necessarily a desirable feature of these auction formats. Bidders might be reluctant to truthfully reveal their full private value if there will be subsequent auctions or negotiations in which

\footnotetext{
${ }^{1}$ The coefficient of proportion depends on the number of players. E.g. for 3 players this coefficient is equal to $\frac{1}{4}$.

${ }^{2}$ The reason is that in the English auction all bidders except a bidder with the highest valuation drop out when the price reaches their valuations.
} 
the information revealed can be used against them. Such considerations lead to an interest in auctions where bidders need not reveal their information entirely but only partially $[2,6,10]$.

So, the question that arises is: how to design an auction that elicits less information about bidders' valuations than the Vickrey and English auctions but still enough to guarantee an efficient allocation. We present an alternative auction format, called the bisection auction, that possesses these properties. In [4] we analyzed equilibrium properties of the bisection auction. We proved that there exists an equilibrium in weakly dominant strategies in which everyone truthfully reveals (part of) his valuation, and the object is allocated in accordance with efficiency requirements to the buyer who has the highest valuation. The primal contribution of this paper is to analyze the issue concerning the revelation of bidders' valuations and associated communication in the bisection auction. We show that the proposed auction is economical in its demand for information. In this auction much less information than the Vickrey and English auctions needs to be revealed to the auctioneer to decide on an allocation and a payment. Only a bidder with the second highest valuation reveals his valuation, something that is inevitable in a Vickrey implementation [3]. Furthermore, in the proposed auction a player can implement the weakly dominant strategy from incomplete preference information, such as lower and upper bounds on value, while implementation of the weakly dominant strategy in the Vickrey auction requires complete knowledge of a player's valuation.

Concerning associated communication we focus on the following issue: the number of information bits ${ }^{3}$ that bidders should transmit during the auctions in the truthtelling equilibrium. We find out that in expectation the corresponding number in the bisection auction is far less than in the Vickrey and English auctions. In order to show this we derive formulas for the expected number of information bits in these auctions with $n$ players whose valuations are integer numbers uniformly and independently drawn from the interval $\left[0,2^{R}\right)$ for some positive integer $R$. While we find that in the Vickrey auction $R n$ information bits and in the English auction at least $\frac{1}{3} n 2^{R}$ information bits are to be transmitted, it turns out that the bisection auction requires transmission of at most $2 n+R$ information bits.

\section{The bisection auction}

Suppose a single indivisible object is auctioned. We assume that buyers are risk neutral. Their valuations are supposed to be integer, randomly drawn from a bounded interval - by default of the form $\left[0,2^{R}\right)$ for some positive integer $R$. The bisection auction has $R$ rounds. The price sequence starts at the middle of the initial interval with a price equal to $2^{R-1}$. Bidders report their demand at the current price by sealed bids. A yes-bid stands for the announcement to be willing to buy at the current price, a no-bid for the contrary. As a function of these bids, the auctioneer announces the price of the next round.

In case there are at least two players submitting a yes-bid, the price goes up to the middle of the upper half interval, i.e. to the interval $\left[2^{R-1}, 2^{R}\right)$. The buyers that are allowed to participate actively in the

\footnotetext{
${ }^{3}$ By bit we mean the smallest unit of information used by a computer, that must be either a 0 or a 1.
} 
next round are the ones that said yes and they are competing for the object in the price range $\left[2^{R-1}, 2^{R}\right)$. The other players drop out of the auction, and do no longer have any influence on the proceedings of the auction. In case there is at most one player saying yes, attention shifts to the lower half interval, i.e. the interval $\left[0,2^{R-1}\right)$ and the price goes down to the middle of this interval. Two different things can happen now. First, the easy case, if no-one has submitted a yes-bid. In that case all active buyers remain active in the next round. In the other case there is a single buyer that submitted a yes-bid. This buyer now becomes the winner and he gets the object. Nevertheless the auction doesn't end, but enters a price-determination phase. The active players in the next round are the ones that were active in the previous round minus the winner. They are competing on the lower half interval $\left[0,2^{R-1}\right) .{ }^{4}$ The winner, although he is no longer considered to be active, is considered to say yes to all prices that are proposed beyond the moment he became the winner. After all, all these prices will be lower than the price he agreed to when he became the winner. Apart from this, the way it is decided whether the price should go up or down is not any different from the way this is decided in the winner-determination phase. In each round depending on submitted bids we subsequently restrict attention to either the lower half of the current interval, or to the upper half of the current interval.

Iterating this procedure will eventually yield a winner ${ }^{5}$ and a price. The price is uniquely determined because in each round the length of the current interval goes down by a factor of two. Since the initial interval is of length $2^{R}$, after $R$ rounds the resulting interval is of length 1 . And since it is a half-open interval, it contains exactly one integer. This integer is declared to be the price the winner of the auction has to pay for the object.

The following example illustrates how the bisection auction works.

Example. Suppose there are four bidders with the following integer private valuations from the interval $[0,16)$ :

\begin{tabular}{|c|c|}
\hline bidder $\mathrm{A}$ & 11 \\
\hline bidder $\mathrm{B}$ & 7 \\
\hline bidder $\mathrm{C}$ & 15 \\
\hline bidder $\mathrm{D}$ & 9 \\
\hline
\end{tabular}

To determine the winner and the price in this setting the bisection auction takes four rounds and starts with the initial ask price equal to 8. Suppose that each player chooses to respond truthfully and follows a straightforward strategy under which he says yes if an ask price is less or equal to his valuation and no otherwise. Then the responses of bidders in the first round are as follows:

Round 1:

\begin{tabular}{|c|c|c|c|c|c|c|}
\hline price & lower bound & upper bound & bidder A & bidder B & bidder C & bidder D \\
\hline 8 & 0 & 16 & yes & no & yes & yes \\
\hline
\end{tabular}

\footnotetext{
${ }^{4}$ In order to keep active buyers motivated to participate in the auction they should not get to know that the object has already been assigned. Therefore we assume that bidders aren't able to observe bids of the others.

${ }^{5}$ Unless in no round there was precisely one player that said yes. In that case several players will still be active after $R$ rounds, and the object is assigned by a lottery.
} 
Since three bidders submitted yes-bids the price increases to the middle of the current price and the current upper bound. So the ask price of the second round is 12 . These three players remain active while player B drops out. Active players are free to submit any bids they want while a drop-out is only allowed to submit no-bids. In the second round players act as follows:

$\underline{\text { Round 2: }}$

\begin{tabular}{|c|c|c|c|c|c|c|}
\hline price & lower bound & upper bound & bidder A & bidder B & bidder C & bidder D \\
\hline 12 & 8 & 16 & no & no & yes & no \\
\hline
\end{tabular}

Since there is only one yes-bid we have a winner and we enter the price determination phase. The winner, player $\mathrm{C}$, becomes inactive and in the remaining rounds may submit only yes-bids. Players A and $\mathrm{D}$ are still active. The ask price decreases to 10 and responses of players in the third rounds are:

$\underline{\text { Round 3: }}$

\begin{tabular}{|c|c|c|c|c|c|c|}
\hline price & lower bound & upper bound & bidder A & bidder B & bidder C & bidder D \\
\hline 10 & 8 & 12 & yes & no & yes & no \\
\hline
\end{tabular}

There are two yes-bids so the price increases. Player D drops out. To the ask price of 11 the responses of players are as follows (notice that the only player who is free to submit any bid in this last round is player A, who is still active; players B and D may submit only no-bids since they are drop-outs, player $\mathrm{C}$ may submit only yes-bids since he is the winner):

Round 4:

\begin{tabular}{|c|c|c|c|c|c|c|}
\hline price & lower bound & upper bound & bidder A & bidder B & bidder C & bidder D \\
\hline 11 & 10 & 12 & yes & no & yes & no \\
\hline
\end{tabular}

At this round the auction terminates. Taking into account bids made during the last round we compute the final lower and upper bounds. Since there were 2 yes-bids the upper bound remains to be 12 while the lower bound becomes 11. At the price of 11 we have demand from bidders $\mathrm{A}$ and $\mathrm{C}$ while at a price of 12 we have demand only from bidder $\mathrm{C}$. So, bidder $\mathrm{C}$ as the winner takes the object and pays price 11 which is the smallest Walrasian price for the demand announced by the bidders that participated in this auction.

Observe that the outcome is efficient: the auction has put the object in the hands of the bidder who values it the most. Also observe that the auction has exactly replicated the outcome of the Vickrey auction since the price the winner pays for the object is equal to the second highest valuation.

In [4] we proved that truth-telling is a weakly-dominant strategy in the bisection auction and that the corresponding equilibrium has an efficient outcome. Analyzing the strategic possibilities of the players in the bisection auction we proved that every strategy that a player can choose has a realization-equivalent threshold strategy. Such a strategy simply states that the bid is yes if the price mentioned by the auctioneer is lower than the threshold in case, otherwise it is no. Thus we showed that, despite the large strategy space, threshold strategies are sufficient from a strategic point of view. Using this result we 
subsequently showed that the buyer with the highest threshold gets the object and the price the winner pays is equal to the second-highest threshold. Interpreting the thresholds as bids in the Vickrey auction we consequently got the same outcome in the bisection auction as in the Vickrey auction. Thus, we showed that the bisection auction is strategically equivalent to the Vickrey auction (and hence also to the English auction). Strategic equivalence of these auctions implies that, as long as bidders behave rationally, in all these auctions the same bidder will win. Actually bidders will even make the same payments in all three auctions. Thus, like in the Vickrey auction, also in this auction truth-telling - that is, choosing the threshold equal to your valuation - is a weakly dominant strategy and the equilibrium results in an efficient allocation.

\section{$3 \quad$ Information revelation and data transmission in the auctions}

Now we know that telling the truth in the bisection auction is an equilibrium in weakly-dominant strategies, just like it is in the Vickrey and English auctions. This allows us to compare the information bidders are required to reveal about their valuations in equilibrium for all three auctions. We will show that the proposed bisection auction is more economical in its demand for information on the valuations of the players than the Vickrey and the English auctions. The Vickrey auction format requires all participants to reveal all information they have. In the English auction all bidders except a bidder with the highest valuation reveals full information, the reason being that the other players drop out when the price reaches their valuations. In the bisection auction, only a bidder with the second highest valuation reveals his full information. Other bidders do not have to reveal any information about their valuation after they have dropped out or became the winner.

The tool we use to measure the revelation of information is the amount of data that gets transmitted in equilibrium ${ }^{6}$. We calculate and compare the expected number of information bits that are to be transmitted by players before the auctioneer can decide upon allocation and payment in the Vickrey, English and bisection auctions.

\subsection{Data transmission in the bisection auction}

In this subsection we present an implementation of the bisection auction that requires from players transmission of at most $2 n+R$ information bits.

The initial ask price is known to all players before the auction starts. During a round with an ask price $p_{r}$ each active player ${ }^{7}$ submits a bid 0 or 1 where 0 stands for the statement "My valuation is less than $p_{r}$ " and 1 stands for the contrary. So, during a round each active player sends a single bit of information to the auctioneer. After receiving bids from all active players the auctioneer counts the number of 1's

\footnotetext{
${ }^{6}$ Notice that the fact that we have truth telling in equilibrium allows us to identify revelation of information with data transmission.

${ }^{7}$ We don't require inactive players to submit bids since the outcome of the auction does not depend on the actions of inactive players.
} 
and determines who remains active. To each player that participated in this round the auctioneer sends a message 0 or 1 where 0 stands for the announcement that the bidder is not active anymore and 1 stands for the contrary. A player that remains active uses the information about his own previous action to compute the price of the next round ${ }^{8}$ and submits his next bid.

Let's calculate the expected number of information bits which are to be transmitted during the auction from players to the auctioneer. We consider the setting where valuations of players are integer numbers drawn uniformly and independently from the interval $\left[0,2^{R}\right)$, for some integer $R$. We assume that each player follows his truth-telling strategy, i.e. he submits 1 to an ask price that is less than or equal to his true valuation and 0 otherwise. From this assumption it follows that in a round an active player submits 1 or 0 with equal probability. Indeed, any active player in a current round $r$ has a valuation that is uniformly distributed in the interval between the current lower and the current upper bound. Together with the fact that a current ask price lies in the middle of this interval it gives us the desired probability of $1 / 2$.

Let $E_{B A}(n, R)$ denote the expected number of information bits transmitted from players in the auction of $n$ (remaining) active players and $R$ (remaining) rounds in the case the winner is not found yet. Similarly, by $E_{B A}^{*}(n, R)$ we denote the expected number of information bits transmitted from players in the auction of $n$ (remaining) active players and $R$ (remaining) rounds in the case the winner has already been found.

First, we find a recursive formula for $E_{B A}(n, R)$. During the first out of $R$ remaining rounds all active players submit bids, so that $n$ information bits are transmitted. Obviously, if only one round remained, then only $n$ bits are transmitted. So $E_{B A}(n, 1)=n$. For $R>1$ several situations can occur. If during this round the winner happens to be found, then $n-1$ active players (all except the winner) and $R-1$ rounds remain. The probability of this event is equal to $n\left(\frac{1}{2}\right)^{n}$. If during this round the winner is not found then $k$ active players $(2 \leq k \leq n)$ and $R-1$ rounds remain. ${ }^{9}$ For $2 \leq k \leq n-1$ the probability of this to occur is $P(k, n)=\left(\begin{array}{l}n \\ k\end{array}\right)\left(\frac{1}{2}\right)^{n}$ (i.e. the probability that $k$ out of $n$ active players say yes). For $k=n$ the probability of the situation to occur is $P(n, n)=2\left(\frac{1}{2}\right)^{n}$ (i.e the probability that all $n$ players say yes plus the probability that all $n$ players say no). Thus, for $n>1$ and $R>1$ we find that

$$
E_{B A}(n, R)=n+n\left(\frac{1}{2}\right)^{n} E_{B A}^{*}(n-1, R-1)+\sum_{k=2}^{n} P(k, n) E_{B A}(k, R-1) .
$$

Now we derive a recursive formula for $E_{B A}^{*}(n, R)$. To do that we consider a situation where $n$ active players and $R$ rounds remain in the auction and during a previous round the winner was already found. During the first out of $R$ remaining rounds all active players submit bids, so that $n$ information bits are transmitted during this round. Again, if only one round remained, then only $n$ bits are transmitted, so $E_{B A}^{*}(n, 1)=n$. If only one player happens to be active he remains active till the end of the auction and during the remaining $R$ rounds exactly $R$ bits will be submitted, so $E_{B A}^{*}(1, R)=R$. For $n>1$ and

\footnotetext{
${ }^{8}$ Recall that if he said yes in the previous round the price goes up, otherwise the price goes down.

${ }^{9}$ Notice that if the winner is not found the situation with only one active player in the next round can't occur.
} 
$R>1$ several situations can occur. Depending on the bids in this round $k$ active players $(1 \leq k \leq n)$ and $R-1$ rounds remain. For $1 \leq k \leq n-1$ the probability that $k$ active players remain is $P(k, n)=\left(\begin{array}{l}n \\ k\end{array}\right)\left(\frac{1}{2}\right)^{n}$. For $k=n$ this probability is $P(n, n)=2\left(\frac{1}{2}\right)^{n}$. Thus, for $n>1$ and $R>1$ we find that

$$
E_{B A}^{*}(n, R)=n+\sum_{k=1}^{n} P(k, n) E_{B A}^{*}(k, R-1) .
$$

Using these formulas we can compute the expected number of information bits transmitted from the players to the auctioneer in the bisection auction for different combinations of $n$ and $R$. Table 1 presents the computational results for $R$ up to 10 and $n$ up to 20 (within an accuracy of 0.001 ).

\begin{tabular}{|c|rrrrrrrrr|}
\hline$n \backslash R$ & 2 & 3 & 4 & 5 & 6 & 7 & 8 & 9 & 10 \\
\hline 2 & 3.500 & 4.750 & 5.875 & 6.938 & 7.969 & 8.984 & 9.992 & 10.996 & 11.998 \\
3 & 5.250 & 6.938 & 8.297 & 9.480 & 10.573 & 11.619 & 12.643 & 13.655 & 14.661 \\
4 & 6.750 & 8.688 & 10.172 & 11.418 & 12.542 & 13.604 & 14.635 & 15.651 & 16.659 \\
5 & 8.125 & 10.273 & 11.873 & 13.179 & 14.333 & 15.411 & 16.450 & 17.469 & 18.479 \\
6 & 9.468 & 11.818 & 13.530 & 14.895 & 16.080 & 17.173 & 18.220 & 19.243 & 20.255 \\
7 & 10.828 & 13.373 & 15.194 & 16.618 & 17.833 & 18.942 & 19.996 & 21.023 & 22.037 \\
8 & 12.218 & 14.954 & 16.882 & 18.364 & 19.610 & 20.734 & 21.796 & 22.827 & 23.843 \\
9 & 13.641 & 16.562 & 18.597 & 20.136 & 21.411 & 22.551 & 23.620 & 24.656 & 25.673 \\
10 & 15.088 & 18.195 & 20.333 & 21.929 & 23.234 & 24.389 & 25.466 & 26.505 & 27.525 \\
11 & 16.554 & 19.847 & 22.086 & 23.739 & 25.073 & 26.243 & 27.328 & 28.371 & 29.393 \\
12 & 18.032 & 21.513 & 23.853 & 25.561 & 26.925 & 28.109 & 29.203 & 30.249 & 31.273 \\
13 & 19.519 & 23.190 & 25.629 & 27.392 & 28.785 & 29.985 & 31.086 & 32.137 & 33.162 \\
14 & 21.011 & 24.877 & 27.413 & 29.230 & 30.653 & 31.868 & 32.976 & 34.031 & 35.058 \\
15 & 22.506 & 26.571 & 29.204 & 31.075 & 32.527 & 33.757 & 34.873 & 35.932 & 36.961 \\
16 & 24.007 & 28.273 & 31.001 & 32.926 & 34.406 & 35.652 & 36.775 & 37.837 & 38.869 \\
17 & 25.502 & 29.980 & 32.804 & 34.781 & 36.291 & 37.551 & 38.682 & 39.748 & 40.781 \\
18 & 27.001 & 31.693 & 34.612 & 36.642 & 38.179 & 39.455 & 40.594 & 41.664 & 42.699 \\
19 & 28.501 & 33.412 & 36.424 & 38.506 & 40.073 & 41.363 & 42.509 & 43.583 & 44.620 \\
20 & 30.000 & 35.134 & 38.242 & 40.375 & 41.970 & 43.275 & 44.429 & 45.506 & 46.545 \\
\hline
\end{tabular}

Table 1: The expected number of information bits transmitted from the players to the auctioneer in the bisection auction of $n$ players and $R$ rounds, $E_{B A}(n, R)$.

In general we can show that both $E_{B A}^{*}(n, R)$ and $E_{B A}(n, R)$ have upper bounds that are linear in $n$ and $R$, namely that $E_{B A}^{*}(n, R) \leq 2 n+R-2$ and $E_{B A}(n, R) \leq 2 n+R$.

Lemma 3.1 For any $n \in \mathbb{N}$ and $R \in \mathbb{N}, \quad E_{B A}^{*}(n, R) \leq 2 n+R-2$.

Proof. The proof is by induction on $R$. Our induction proposition is $P(R)$ : for every $n \in \mathbb{N} \quad E_{B A}^{*}(n, R) \leq 2 n+R-2$.

The basis of induction, $P(1)$, is trivial since $E_{B A}^{*}(n, 1)=n \leq 2 n+1-2=2 n-1$ is true for any $n \in \mathbb{N}$. Now suppose that the proposition $P(R-1)$ is true. Let us show that $P(R)$ is also true. 
So, take $n \in \mathbb{N}$.

If $n=1$ then we have $E_{B A}^{*}(1, R)=R \leq 2+R-2=R$ is true;

If $n>1$ then, using the induction hypothesis,

$$
\begin{aligned}
E_{B A}^{*}(n, R) & =n+\sum_{k=1}^{n} P(k, n) E_{B A}^{*}(k, R-1) \\
& =n+\sum_{k=1}^{n-1}\left(\begin{array}{l}
n \\
k
\end{array}\right)\left(\frac{1}{2}\right)^{n} E_{B A}^{*}(k, R-1)+2\left(\frac{1}{2}\right)^{n} E_{B A}^{*}(n, R-1) \\
& \leq n+\sum_{k=1}^{n-1}\left(\begin{array}{l}
n \\
k
\end{array}\right)\left(\frac{1}{2}\right)^{n}(2 k+R-3)+2\left(\frac{1}{2}\right)^{n}(2 n+R-3) \\
& =n+\sum_{k=1}^{n-1}\left(\begin{array}{l}
n \\
k
\end{array}\right)\left(\frac{1}{2}\right)^{n} 2 k+4 n\left(\frac{1}{2}\right)^{n}+\sum_{k=1}^{n-1}\left(\begin{array}{l}
n \\
k
\end{array}\right)\left(\frac{1}{2}\right)^{n}(R-3)+2\left(\frac{1}{2}\right)^{n}(R-3) \\
& =n+2 \sum_{k=0}^{n}\left(\begin{array}{l}
n \\
k
\end{array}\right)\left(\frac{1}{2}\right)^{n} k+2 n\left(\frac{1}{2}\right)^{n}+\sum_{k=0}^{n}\left(\begin{array}{l}
n \\
k
\end{array}\right)\left(\frac{1}{2}\right)^{n}(R-3) \\
& =2 n+2 n\left(\frac{1}{2}\right)^{n}+R-3 .
\end{aligned}
$$

Since for any $n$ it holds that $2 n\left(\frac{1}{2}\right)^{n} \leq 1$ we have the desired inequality $E_{B A}^{*}(n, R) \leq 2 n+R-2$.

Theorem 3.2 For any integer $n \geq 2$ and $R \in \mathbb{N}, \quad E_{B A}(n, R) \leq 2 n+R$.

Proof. The proof is by induction on $R$. Our induction proposition is $P(R)$ : for every integer $n \geq 2 \quad E_{B A}(n, R) \leq 2 n+R$.

The basis of induction, $P(1)$, is trivial since $E_{B A}(n, 1)=n \leq 2 n+1$ is true for any integer $n \geq 2$. Now suppose that the proposition $P(R-1)$ is true. Let us show that $P(R)$ is also true.

So, take an integer $n \geq 2$. Using the induction hypothesis and the result of Lemma 3.1 we have

$$
\begin{aligned}
E_{B A}(n, R)= & n+n\left(\frac{1}{2}\right)^{n} E_{B A}^{*}(n-1, R-1)+\sum_{k=2}^{n} P(k, n) E_{B A}(k, R-1) \\
= & n+n\left(\frac{1}{2}\right)^{n} E_{B A}^{*}(n-1, R-1)+\sum_{k=2}^{n-1}\left(\begin{array}{l}
n \\
k
\end{array}\right)\left(\frac{1}{2}\right)^{n} E_{B A}(k, R-1)+2\left(\frac{1}{2}\right)^{n} E_{B A}(n, R-1) \\
\leq & n+n\left(\frac{1}{2}\right)^{n}(2 n+R-5)+\sum_{k=2}^{n-1}\left(\begin{array}{l}
n \\
k
\end{array}\right)\left(\frac{1}{2}\right)^{n}(2 k+R-1)+2\left(\frac{1}{2}\right)^{n}(2 n+R-1) \\
= & n+2 n^{2}\left(\frac{1}{2}\right)^{n}+n\left(\frac{1}{2}\right)^{n}(R-5)+2 \sum_{k=2}^{n-1}\left(\begin{array}{l}
n \\
k
\end{array}\right)\left(\frac{1}{2}\right)^{n} k+4 n\left(\frac{1}{2}\right)^{n}+ \\
& \sum_{k=2}^{n-1}\left(\begin{array}{l}
n \\
k
\end{array}\right)\left(\frac{1}{2}\right)^{n}(R-1)+2\left(\frac{1}{2}\right)^{n}(R-1)
\end{aligned}
$$




$$
\begin{aligned}
= & n+2 n^{2}\left(\frac{1}{2}\right)^{n}+n\left(\frac{1}{2}\right)^{n}(R-5)+2 \sum_{k=0}^{n}\left(\begin{array}{l}
n \\
k
\end{array}\right)\left(\frac{1}{2}\right)^{n} k+ \\
& \sum_{k=0}^{n}\left(\begin{array}{l}
n \\
k
\end{array}\right)\left(\frac{1}{2}\right)^{n}(R-1)-n\left(\frac{1}{2}\right)^{n}(R-1) \\
= & n+2 n^{2}\left(\frac{1}{2}\right)^{n}+n\left(\frac{1}{2}\right)^{n}(R-5)+n+R-1-n\left(\frac{1}{2}\right)^{n}(R-1) \\
= & 2 n+R+2 n^{2}\left(\frac{1}{2}\right)^{n}-4 n\left(\frac{1}{2}\right)^{n}-1 \\
= & 2 n+R+\left(\frac{1}{2}\right)^{n}\left(2 n^{2}-4 n\right)-1 .
\end{aligned}
$$

It is straightforward to check that $f(n)=\left(\frac{1}{2}\right)^{n}\left(2 n^{2}-4 n\right) \leq 1$ for any integer $n \geq 1$. Thus the desired inequality $E_{B A}(n, R) \leq 2 n+R$ holds.

So we can conclude that during the bisection auction on average not more than $2 n+R$ bits are transmitted from players to the auctioneer.

Concerning a lower bound, it is easy to see that during the bisection auction at least $n+R-1$ information bits are to be transmitted from players to the auctioneer. Indeed, during the first round all $n$ active players send a bit and there is at least one active player during the remaining $R-1$ rounds.

\subsection{Comparison with the English auction}

The English auction starts with an ask price equal to 1. From round to round the price increases by a unit increment as long as at least two players announce their willingness to pay. So, after each round the auctioneer communicates the new price and active players announce whether they are willing to buy or not. For the equilibrium in weakly dominant strategies in which players reply truthfully, the number of rounds is equal to the second highest valuation. Let us assume that only a synchronization signal is submitted: the auctioneer communicates price increments to all active players by sending 1 , while he communicates the end of the auction by sending 0. Players update their price based on this signal and send 1 to the auctioneer if they stay active and 0 otherwise.

As in the bisection auction, we calculate the expected number of information bits which are to be transmitted during the auction from players to the auctioneer. Suppose that valuations of players are integer numbers uniformly and independently drawn from the interval $[0, L)$ for some integer $L$. We assume that all players follow their truth-telling strategies. In the first round with an ask price equal to 1 the probability that a player says yes is equal to the probability that his valuation is not equal to 0 which is $\frac{L-1}{L}$. For any player $i$ who remains active in the next round it holds that $v_{i} \in[1, L)$. So, the probability of saying yes in the second round (i.e the probability of having valuation not equal to 1 ) given that the player is active is equal to $\frac{L-2}{L-1}$. And so on.

With $n$ active players in a round there will be $2 \leq k \leq n$ active players in the next round. By $P(k, n, L)$ we denote the probability that exactly $k$ out of $n$ active players, whose valuations are random integer 
numbers from a half open interval of length $L$, say yes.

$$
P(k, n, L)=\left(\begin{array}{l}
n \\
k
\end{array}\right)\left(\frac{L-1}{L}\right)^{k}\left(\frac{1}{L}\right)^{n-k}
$$

Let's denote by $E_{E N}(n, L)$ the expected number of information bits transmitted from players in the auction of $n$ active players whose valuations are random integer numbers from a half open interval of length $L$. Notice that for $L=2, E_{E N}(n, 2)=n$. For $L \geq 3$ and $n \geq 2$ we find that

$$
E_{E N}(n, L)=n+\sum_{k=2}^{n} P(k, n, L) E_{E N}(k, L-1)=n+\sum_{k=2}^{n}\left(\begin{array}{l}
n \\
k
\end{array}\right)\left(\frac{L-1}{L}\right)^{k}\left(\frac{1}{L}\right)^{n-k} E_{E N}(k, L-1)
$$

We can show that $E_{E N}(n, L)$ has a lower bound that is bilinear in $n$ and $L$.

Theorem 3.3 For any integer $n \geq 2$ and $L \geq 2, \quad E_{E N}(n, L) \geq \frac{1}{3} L n$.

Proof. The proof is by induction on $L$.

Our induction proposition is $P(L)$ : for every integer $n \geq 2 \quad E_{E N}(n, L) \geq \frac{1}{3} L n$.

The basis of induction, $P(2)$, is trivial since $E_{E N}(n, 2)=n \geq \frac{1}{3} n$ is true for any integer $n \geq 2$. Now suppose that the proposition $P(L-1)$ is true. Let us show that $P(L)$ is also true.

So, take an integer $n \geq 2$. To prove: $E_{E N}(n, L) \geq \frac{1}{3} L n$. Using the induction hypothesis we have

$$
\begin{aligned}
E_{E N}(n, L) & =n+\sum_{k=2}^{n}\left(\begin{array}{l}
n \\
k
\end{array}\right)\left(\frac{L-1}{L}\right)^{k}\left(\frac{1}{L}\right)^{n-k} E_{E N}(k, L-1) \\
& \geq n+\sum_{k=2}^{n}\left(\begin{array}{l}
n \\
k
\end{array}\right)\left(\frac{L-1}{L}\right)^{k}\left(\frac{1}{L}\right)^{n-k} \frac{1}{3}(L-1) k \\
& =n+\frac{1}{3}(L-1)\left[\sum_{k=0}^{n}\left(\begin{array}{l}
n \\
k
\end{array}\right)\left(\frac{L-1}{L}\right)^{k}\left(\frac{1}{L}\right)^{n-k} k-n\left(\frac{L-1}{L}\right)\left(\frac{1}{L}\right)^{n-1}\right] \\
& =n+\frac{1}{3}(L-1)\left[\left(\frac{L-1}{L}\right) n-n\left(\frac{L-1}{L}\right)\left(\frac{1}{L}\right)^{n-1}\right] \\
& =\frac{1}{3} n L+n\left(\frac{2}{3}-\frac{1}{3}\left(\frac{L-1}{L}+\frac{(L-1)^{2}}{L^{n}}\right)\right) .
\end{aligned}
$$

Since for any $L$ and any $n \geq 2$ it holds that $\frac{L-1}{L} \leq 1$ and $\frac{(L-1)^{2}}{L^{n}} \leq 1$ we have the desired inequality $E_{E N}(n, L) \geq \frac{1}{3} L n$.

So we can conclude that during the English auction on average at least $\frac{1}{3} L n$ bits are to be transmitted from players to the auctioneer.

To compare the considered communication performance of the bisection and English auctions we look at the same range of valuations for both auctions. So we take interval $\left[0,2^{R}\right)$ and compare $E_{B A}(n, R)$ with $E_{E N}\left(n, 2^{R}\right)$. For valuations uniformly and independently drawn from the interval $\left[0,2^{R}\right)$ the bisection 
auction requires from players in expectation transmission of at most $2 n+R$ information bits while the English auction requires transmission of at least $\frac{1}{3} 2^{R} n$ bits.

It can easily be checked that for any $R \geq 4$ and any $n$ the upper bound of the expected number of bits transmitted by players in the bisection auction is less than the corresponding lower bound in the English auction. Moreover it can be shown that for all $n$ and $R$ it holds that $E_{B A}(n, R) \leq E_{E N}\left(n, 2^{R}\right)$. Concerning the limit behaviour of both auctions, from the above bounds, it can easily be seen that for all $n$ the ratio $E_{E N}\left(n, 2^{R}\right) / E_{B A}(n, R)$ tends to infinity as $R \rightarrow \infty$. In particular, the expected number of information bits required by the English auction is exponential in the total expected number of information bits required by the bisection auction. Thus we can conclude that the bisection auction requires from players in expectation communication of far less information bits than the English auction.

\subsection{Comparison with the Vickrey auction}

To compare the considered communication performance of the bisection and Vickrey auctions we look again at valuations uniformly and independently drawn from the interval $\left[0,2^{R}\right)$. Any valuation from this interval can be represented using a binary encoding of length $R$. Submission of a valuation expressed in this way consists of $R$ information bits. Since during the Vickrey auction all players submit their exact valuation, this auction of $n$ players requires communication of $R n$ bits.

It can be shown by induction (in the same way as it was done in Subsection 3.1) that for any $n$ and $R$ the expected number of bits transmitted from players in the bisection auction, $E_{B A}(n, R)$, is less than the number of corresponding bits in the Vickrey auction, $R n$. Thus, we can conclude that the bisection auction requires from players in expectation far less communication than the Vickrey auction.

\section{Conclusions}

We proposed a new efficient incentive-compatible auction, the bisection auction, and analyzed its information revelation and corresponding communication requirements. We have shown that participation in the proposed auction is less demanding than in the Vickrey and English auctions. In the bisection auction less information needs to be revealed to the auctioneer to decide on an allocation and a payment. While in the Vickrey auction all players and in the English auction all except a bidder with the highest valuation need to reveal their valuation, in the bisection auction only the bidder with the second highest valuation has to reveal this.

Furthermore, we have shown that in the truthtelling equilibrium bidders transmit in expectation far less information bits in the bisection auction than in the Vickrey and English auctions. In particular, when the value range increases, the expected number of bits in the English auction grows exponentially w.r.t. the expected number of bits in the bisection auction. 


\section{References}

[1] Clarke, E.H. [1971] Multipart Pricing of Public Goods. Public Choice, XI, 17-33.

[2] Engelbrecht-Wiggans, R. and Kahn, C.M. [1991] Protecting the Winner: Second-price versus oral auctions. Economics Letters, 35(3), 243-248.

[3] Green, J. and Laffont, J-J. [1977] Characterization of satisfactory mechanisms for the revelation of preferences for public goods. Econometrica, 45, 427-438.

[4] Grigorieva, E., Herings, P.J-J., Muller, R. and Vermeulen, D. [2002] The private value single item bisection auction. Research Memoranda, Maastricht Research School of Economics of Technology and Organization, RM/02/035. Availabe from http://edata.ub.unimaas.nl/wwwedocs/loader/file.asp?id $=675$

[5] Groves, T. [1973] Incentives in teams. Econometrica, 61, 617-631.

[6] Kagel, J.H., Hartstad, R.M. and Levin, D. [1987] Information impact and allocation rules in auctions with affiliated private values: a laboratory study. Econometrica, 55, 1275-1304.

[7] Mas-Colell, A., Whinston, M. and Green, J [1995] Microeconomic Theory. New York, Oxford University Press.

[8] Nisan, N. and Segal, I. [2001] The communication complexity of efficient allocation problems. Technical report, Hebrew University and Stanford University. Available from http://www.cs.huji.ac.il/ noam/mkts.html

[9] Nisan, N. and Blumrosen, L. [2002] Auctions with severely bounded communication. Proccedings of 43th Annual Symposium on Foundations of Computer Science.

[10] Rothkopf, M.H., Tisberg, T.J. and Kahn, E.P. [1990] Why are Vickrey auctions rare? Journal of Political Economy, 98, 94-109.

[11] Rothkopf, M.H. and Harstad, R.M. [1994] On the role of discrete bid levels in oral auctions. European Journal of Operational Research, 74, 572-581.

[12] Vickrey, W. [1961] Counterspeculation, auctions and competitive sealed tenders. Journal of Finance, $16,8-37$. 